Perspective

\title{
Improving Bioscience Research Reporting: The ARRIVE Guidelines for Reporting Animal Research ${ }^{\dagger}$
}

\author{
Carol Kilkenny ${ }^{1, *}$, William J. Browne ${ }^{2}$, Innes C. Cuthill ${ }^{3}$, Michael Emerson ${ }^{4}$ and \\ Douglas G. Altman ${ }^{5}$
}

1 The National Centre for the Replacement, Refinement and Reduction of Animals in Research, London, UK

2 School of Veterinary Science, University of Bristol, Bristol, UK

3 School of Biological Sciences, University of Bristol, Bristol, UK

4 National Heart and Lung Institute, Imperial College London, London, UK

5 Centre for Statistics in Medicine, University of Oxford, Oxford, UK

This article was previously published by PLoS Biology: Kilkenny, C.; Browne, W.J.; Cuthill, I.C.; Emerson, M.; Altman, D.G. Improving Bioscience Research Reporting: The ARRIVE Guidelines for Reporting Animal Research. PLoS Biol. 2010, 8, doi:10.1371/journal.pbio.1000412.

* Author to whom correspondence should be addressed; E-Mail: ARRIVE@nc3rs.org.uk.

Received: 20 January 2014 / Accepted: 31 January 2014 / Published: 3 February 2014

\section{Abbreviations}

ARRIVE Animals in Research: Reporting In Vivo Experiments

NC3Rs National Centre for the Replacement, Refinement and Reduction of Animals in Research

In the last decade the number of bioscience journals has increased enormously, with many filling specialised niches reflecting new disciplines and technologies. The emergence of open-access journals has revolutionised the publication process, maximising the availability of research data. Nevertheless, a wealth of evidence shows that across many areas, the reporting of biomedical research is often inadequate, leading to the view that even if the science is sound, in many cases the publications themselves are not "fit for purpose", meaning that incomplete reporting of relevant information effectively renders many publications of limited value as instruments to inform policy or clinical and scientific practice [1-21]. A recent review of clinical research showed that there is considerable cumulative waste of financial resources at all stages of the research process, including as a result of 
publications that are unusable due to poor reporting [22]. It is unlikely that this issue is confined to clinical research [2-14,16-20].

Failure to describe research methods and to report results appropriately therefore has potential scientific, ethical, and economic implications for the entire research process and the reputation of those involved in it. This is particularly true for animal research, one of the most controversial areas of science. The largest and most comprehensive review of published animal research undertaken to date, to our knowledge, has highlighted serious omissions in the way research using animals is reported [5]. The survey, commissioned by the National Centre for the Replacement, Refinement and Reduction of Animals in Research (NC3Rs), a UK Government-sponsored scientific organisation, found that only $59 \%$ of the 271 randomly chosen articles assessed stated the hypothesis or objective of the study, and the number and characteristics of the animals used (i.e., species/strain, sex, and age/weight). Most of the papers surveyed did not report using randomisation $(87 \%)$ or blinding $(86 \%)$ to reduce bias in animal selection and outcome assessment. Only $70 \%$ of the publications that used statistical methods fully described them and presented the results with a measure of precision or variability [5]. These findings are a cause for concern and are consistent with reviews of many research areas, including clinical studies, published in recent years [2-22].

\section{Good Reporting Is Essential for Peer Review and to Inform Future Research}

Scrutiny by scientific peers has long been the mainstay of "quality control" for the publication process. The way that experiments are reported, in terms of the level of detail of methods and the presentation of key results, is crucial to the peer review process and, indeed, the subsequent utility and validity of the knowledge base that is used to inform future research. The onus is therefore on the research community to ensure that their research articles include all relevant information to allow indepth critique, and to avoiding duplicating studies and performing redundant experiments. Ideally scientific publications should present sufficient information to allow a knowledgeable reader to understand what was done, why, and how, and to assess the biological relevance of the study and the reliability and validity of the findings. There should also be enough information to allow the experiment to be repeated [23]. The problem therefore is how to ensure that all relevant information is included in research publications.

\section{Using Reporting Guidelines Measurably Improves the Quality of Reporting}

Evidence provided by reviews of published research suggests that many researchers and peer reviewers would benefit from guidance about what information should be provided in a research article. The CONSORT Statement for randomised controlled clinical trials was one of the first guidelines developed in response to this need [24,25]. Since publication, an increasing number of leading journals have supported CONSORT as part of their instructions to authors [26,27]. As a result, convincing evidence is emerging that CONSORT improves the quality and transparency of reports of clinical trials [28,29].

Following CONSORT, many other guidelines have been developed - there are currently more than 90 available for reporting different types of health research, most of which have been published in the last ten years (see http://www.equator-network.org and references [30,31]). Guidelines have also been 
developed to improve the reporting of other specific bioscience research areas including metabolomics and gene expression studies [32-37]. Several organisations support the case for improved reporting and recommend the use of reporting guidelines, including the International Committee of Medical Journal Editors, the Council of Science Editors, the Committee on Publication Ethics, and the Nuffield Council for Bioethics [38-41].

\section{Improving the Reporting of Animal Experiments-The ARRIVE Guidelines}

Most bioscience journals currently provide little or no guidance on what information to report when describing animal research [42-50]. Our review found that $4 \%$ of the 271 journal articles assessed did not report the number of animals used anywhere in the methods or the results sections [5]. Reporting animal numbers is essential so that the biological and statistical significance of the experimental results can be assessed or the data reanalysed, and is also necessary if the experimental methods are to be repeated. Improved reporting of these and other details will maximise the availability and utility of the information gained from every animal and every experiment, preventing unnecessary animal use in the future. To address this, we led an initiative to produce guidelines for reporting animal research. The guidelines, referred to as ARRIVE (Animals in Research: Reporting In Vivo Experiments), have been developed using the CONSORT Statement as their foundation [24,25].

The ARRIVE guidelines consist of a checklist of 20 items describing the minimum information that all scientific publications reporting research using animals should include, such as the number and specific characteristics of animals used (including species, strain, sex, and genetic background); details of housing and husbandry; and the experimental, statistical, and analytical methods (including details of methods used to reduce bias such as randomisation and blinding). All the items in the checklist have been included to promote high-quality, comprehensive reporting to allow an accurate critical review of what was done and what was found.

Consensus and consultation are the corner-stones of the guideline development process [51]. To maximise their utility, the ARRIVE guidelines have been prepared in consultation with scientists, statisticians, journal editors, and research funders. We convened an expert working group, comprising researchers and statisticians from a range of disciplines, and journal editors from Nature Cell Biology, Science, Laboratory Animals, and the British Journal of Pharmacology (see Acknowledgments). At a one-day meeting in June 2009, the working group agreed the scope and broad content of a draft set of guidelines that were then used as the basis for a wider consultation with the scientific community, involving researchers, and grant holders and representatives of the major bioscience funding bodies including the Medical Research Council, Wellcome Trust, Biotechnology and Biological Sciences Research Council, and The Royal Society (see Table 1). Feedback on the content and wording of the items was incorporated into the final version of the checklist. Further feedback on the content utility of the guidelines is encouraged and sought.

The ARRIVE guidelines (see Table 2) can be applied to any area of bioscience research using laboratory animals, and the inherent principles apply not only to reporting comparative experiments but also to other study designs. Laboratory animal refers to any species of animal undergoing an experimental procedure in a research laboratory or formal test setting. The guidelines are not intended to be mandatory or absolutely prescriptive, nor to standardise or formalise the structure of reporting. 
Rather they provide a checklist that can be used to guide authors preparing manuscripts for publication, and by those involved in peer review for quality assurance, to ensure completeness and transparency.

\section{Improved Reporting Will Maximise the Output of Published Research}

These guidelines were developed to maximise the output from research using animals by optimising the information that is provided in publications on the design, conduct, and analysis of the experiments. The need for such guidelines is further illustrated by the systematic reviews of animal research that have been carried out to assess the efficacy of various drugs and interventions in animal models $[8,9,13,52-55]$. Well-designed and -reported animal studies are the essential building blocks from which such a systematic review is constructed. The reviews have found that, in many cases, reporting omissions, in addition to the limitations of the animal models used in the individual studies assessed in the review, are a barrier to reaching any useful conclusion about the efficacy of the drugs and interventions being compared [2,3].

Driving improvements in reporting research using animals will require the collective efforts of authors, journal editors, peer reviewers, and funding bodies. There is no single simple or rapid solution, but the ARRIVE guidelines provide a practical resource to aid these improvements. The guidelines will be published in several leading bioscience research journals simultaneously [56-60], and publishers have already endorsed the guidelines by including them in their journal Instructions to Authors subsequent to publication. The NC3Rs will continue to work with journal editors to extend the range of journals adopting the guidelines, and with the scientific community to disseminate the guidelines as widely as possible (http://www.nc3rs.org.uk/ARRIVE).

Table 1. Funding bodies consulted.

\begin{tabular}{|l}
\hline Name of Bioscience Research Funding Body \\
\hline Medical Research Council \\
Biotechnology and Biological Sciences Research \\
Council \\
Wellcome Trust \\
The Royal Society \\
Association of Medical Research Charities \\
British Heart Foundation \\
Parkinson's Disease Society \\
\hline doi:10.1371/journal.pbio.1000412.t001
\end{tabular}


Table 2. Animal Research: Reporting In Vivo Experiments: The ARRIVE guidelines.

\begin{tabular}{|c|c|c|}
\hline TITLE & 1 & Provide as accurate and concise a description of the content of the article as possible. \\
\hline \multicolumn{3}{|l|}{ INTRODUCTION } \\
\hline Objectives & 4 & $\begin{array}{l}\text { Clearly describe the primary and any secondary objectives of the study, or specific hypotheses being } \\
\text { tested. }\end{array}$ \\
\hline \multicolumn{3}{|l|}{ METHODS } \\
\hline Ethical statement & 5 & $\begin{array}{l}\text { Indicate the nature of the ethical review permissions, relevant licences (e.g. Animal [Scientific Procedures] } \\
\text { Act 1986), and national or institutional guidelines for the care and use of animals, that cover the research. }\end{array}$ \\
\hline Experimental procedures & 7 & $\begin{array}{l}\text { For each experiment and each experimental group, including controls, provide precise details of all } \\
\text { procedures carried out. For example: } \\
\text { a. How (e.g., drug formulation and dose, site and route of administration, anaesthesia and analgesia } \\
\text { used [including monitoring], surgical procedure, method of euthanasia). Provide details of any specialist } \\
\text { equipment used, including supplier(s). } \\
\text { b. When (e.g., time of day). } \\
\text { c. Where (e.g., home cage, laboratory, water maze). } \\
\text { d. Why (e.g., rationale for choice of specific anaesthetic, route of administration, drug dose used). }\end{array}$ \\
\hline Experimental animals & 8 & $\begin{array}{l}\text { a. Provide details of the animals used, including species, strain, sex, developmental stage (e.g., mean or } \\
\text { median age plus age range), and weight (e.g., mean or median weight plus weight range). } \\
\text { b. Provide further relevant information such as the source of animals, international strain nomenclature, } \\
\text { genetic modification status (e.g. knock-out or transgenic), genotype, health/immune status, drug- or test- } \\
\text { naive, previous procedures, etc. }\end{array}$ \\
\hline Sample size & 10 & $\begin{array}{l}\text { a. Specify the total number of animals used in each experiment and the number of animals in each } \\
\text { experimental group. } \\
\text { b. Explain how the number of animals was decided. Provide details of any sample size calculation used. } \\
\text { c. Indicate the number of independent replications of each experiment, if relevant. }\end{array}$ \\
\hline $\begin{array}{l}\text { Allocating animals to } \\
\text { experimental groups }\end{array}$ & 11 & $\begin{array}{l}\text { a. Give full details of how animals were allocated to experimental groups, including randomisation or } \\
\text { matching if done. } \\
\text { b. Describe the order in which the animals in the different experimental groups were treated and } \\
\text { assessed. }\end{array}$ \\
\hline Experimental outcomes & 12 & $\begin{array}{l}\text { Clearly define the primary and secondary experimental outcomes assessed (e.g., cell death, molecular } \\
\text { markers, behavioural changes). }\end{array}$ \\
\hline Statistical methods & 13 & $\begin{array}{l}\text { a. Provide details of the statistical methods used for each analysis. } \\
\text { b. Specify the unit of analysis for each dataset (e.g. single animal, group of animals, single neuron). } \\
\text { c. Describe any methods used to assess whether the data met the assumptions of the statistical } \\
\text { approach. }\end{array}$ \\
\hline \multicolumn{3}{|l|}{ RESULTS } \\
\hline Baseline data & 14 & $\begin{array}{l}\text { For each experimental group, report relevant characteristics and health status of animals (e.g., weight, } \\
\text { microbiological status, and drug- or test-naive) before treatment or testing (this information can often be } \\
\text { tabulated). }\end{array}$ \\
\hline Numbers analysed & 15 & $\begin{array}{l}\text { a. Report the number of animals in each group included in each analysis. Report absolute numbers (e.g. } \\
10 / 20 \text {, not } 50 \%^{\mathrm{a}} \text { ). } \\
\text { b. If any animals or data were not included in the analysis, explain why. }\end{array}$ \\
\hline Outcomes and estimation & 16 & $\begin{array}{l}\text { Report the results for each analysis carried out, with a measure of precision (e.g., standard error or } \\
\text { confidence interval). }\end{array}$ \\
\hline
\end{tabular}




\section{Acknowledgments}

This project was initiated, funded, and led by the National Centre for the Replacement, Refinement and Reduction of Animals in Research (NC3Rs).

The NC3Rs gratefully acknowledges the expertise and advice that all the contributors have given to developing the guidelines. We would particularly like to acknowledge the contribution of the other members of NC3Rs Reporting Guidelines Working Group (note that the working group members and authors who contributed to these guidelines were advising in their personal capacity and their input does not necessarily represent the policy of the organisations with which they are associated): Professor David Balding, Department of Epidemiology \& Public Health, Imperial College, London UK; Dr Colin Dunn Editor Laboratory Animals (Royal Society of Medicine press); Dr. Stella Hurtley, Senior Editor Science; Professor Ian McGrath Editor-in-Chief British Journal of Pharmacology (Wiley Blackwell publishers); and Dr. Clare Stanford, Department of Psychopharmacology, University College, London UK. We would also like to thank NC3Rs grant holders, the Medical Research Council, Biotechnology and Biological Sciences Research Council, Wellcome Trust, Parkinson's Disease Society, British Heart Foundation and their grant holders and funding committee members who provided feedback on the guidelines; and Dr. Kathryn Chapman and Dr. Vicky Robinson (both NC3Rs) for their help with the manuscript.

\section{Conflicts of Interest}

The authors have declared that no competing interests exist.

\section{References and Notes}

1. Simera, I.; Altman, D.G. Writing a research article that is "fit for purpose": EQUATOR network and reporting guidelines. Evid. Based Med. 2009, 14, 132-134.

2. van der Worp, H.B.; Howells, D.W.; Sena, E.S.; Porritt, M.J.; Rewell, S.; O'Collins, V.; Macleod, M.R. Can animal models of disease reliably inform human studies? PLoS Med. 2010, 7, doi:10.1371/journal.pmed.1000245.

3. Sena, E.S.; van der Worp, H.B.; Bath, P.M.; Howells, D.W.; Macleod, M.R. Publication bias in reports of animal stroke studies leads to major overstatement of efficacy. PLoS Biol. 2010, 8, doi:10.1371/journal.pbio.1000344.

4. Sargeant, J.M.; Thompson, A.; Valcour, J.; Elgie, R.; Saint-Onge, J.; Marcynuk, P.; Snedeker, K. Quality of reporting of clinical trials of dogs and cats and associations with treatment effects. J. Vet. Intern. Med. 2010, 24, 44-50.

5. Kilkenny, C.; Parsons, N.; Kadyszewski, E.; Festing, M.F.; Cuthill, I.C.; Fry, D.; Hutton, J.; Altman, D.G. Survey of the quality of experimental design, statistical analysis and reporting of research using animals. PLoS One 2009, 4, doi:10.1371/journal.pone.0007824.

6. Sargeant, J.M.; Elgie, R.; Valcour, J.; Saint-Onge, J.; Thompson, A.; Marcynuk, P.; Snedeker, K. Methodological quality and completeness of reporting in clinical trials conducted in livestock species. Prev. Vet. Med. 2009, 91, 107-115. 
7. Macleod, M.R.; Fisher, M.; O’Collins, V.; Sena, E.S.; Dirnagl, U.; Bath, P.M.; Buchan, A.; van der Worp, H.B.; Traystman, R.; Minematsu, K.; Donnan, G.A.; Howells, D.W. Good laboratory practice. Preventing introduction of bias at the bench. Stroke 2009, 40, e50-e52.

8. Hainsworth, A.H.; Markus, H.S. Do in vivo experimental models reflect human cerebral small vessel disease? A systematic review. J. Cereb. Blood Flow Metab. 2008, 28, 1877-1891.

9. Rice, A.S.; Cimino-Brown, D.; Eisenach, J.C.; Kontinen, V.K.; Lacroix-Fralish, M.L.; Machin, I.; Preclinical Pain Consortium; Mogil, J.S.; Stöhr, T. Animal models and the prediction of efficacy in clinical trials of analgesic drugs: A critical appraisal and call for uniform reporting standards. Pain 2008, 139, 243-247.

10. Sherwin, C.M. Animal welfare: Reporting details is good science. Nature 2007, 448, doi:10.1038/448251b.

11. Jafari, P.; Azuaje, F. An assessment of recently published gene expression analyses: Reporting experimental design and statistics. BMC Med. Inform. Decis. Mak. 2006, 6, doi:10.1186/14726947-6-27.

12. Hackam, D.G.; Redelmeier, D.A. Translation of research evidence from animals to humans. JAMA 2006, 296, 1731-1732.

13. Perel, P.; Roberts, I.; Sena, E.; Wheble, P.; Briscoe, C.; Sandercock, P.; Macleod, M.; Mignini, L.E.; Jayaram, P.; Khan, K.S. Comparison of treatment effects between animal experiments and clinical trials: Systematic review. BMJ 2006, 334, doi:10.1136/bmj.39048.407928.BE.

14. Macleod, M. What can systematic review and meta-analysis tell us about the experimental data supporting stroke drug development? Int. J. Neuroprot. Neuroregener. 2005, 1, 201.

15. Tooth, L.; Ware, R.; Bain, C.; Purdie, D.M.; Dobson, A. Quality of reporting of observational longitudinal research. Am. J. Epidemiol. 2005, 161, 280-288.

16. Pound, P.; Ebrahim, S.; Sandercock, P.; Bracken, M.B.; Roberts, I. Where is the evidence that animal research benefits humans? BMJ 2004, 328, 514-517.

17. Bennett, L.T.; Adams, M.A. Assessment of ecological effects due to forest harvesting: Approaches and statistical issues. J. Appl. Ecol. 2004, 41, 585-598.

18. Morris, C.E.; Bardin, M.; Berge, O.; Frey-Klett, P.; Fromin, N. Microbial biodiversity: Approaches to experimental design and hypothesis testing in primary scientific literature from 1975 to 1999. Microbiol. Mol. Biol. Rev. 2002, 66, 592-616.

19. Smith, J.A.; Birke, L.; Sadler, D. Reporting animal use in scientific papers. Lab Anim. 1997, 31, 312-317.

20. McCance, I. Assessment of statistical procedures used in papers in the Australian Veterinary Journal. Aust. Vet. J. 1995, 72, 322-328.

21. Pocock, S.J.; Hughes, M.D.; Lee, R.J. Statistical problems in the reporting of clinical trials. A survey of three medical journals. N. Engl. J. Med. 1987, 317, 426-432.

22. Chalmers, I.; Glasziou, P. Avoidable waste in the production and reporting of research evidence. Lancet 2009, 374, 86-89.

23. Festing, M.F.; Altman, D.G. Guidelines for the design and statistical analysis of experiments using laboratory animals. ILAR J. 2002, 43, 244-258. 
24. Schulz, K.F.; Altman, D.G.; Moher, D.; Consort Group. CONSORT 2010 Statement: Updated guidelines for reporting parallel group randomised trials. BMJ 2010, 340, c332.

25. Moher, D.; Schulz, K.F.; Altman, D.G. The CONSORT statement: Revised recommendations for improving the quality of reports of parallel-group randomised trials. Lancet 2001, 357, 1191-1194.

26. Altman, D.G. Endorsement of the CONSORT statement by high impact medical journals: Survey of instructions for authors. BMJ 2005, 330, 1056-1057.

27. Hopewell, S.; Altman, D.G.; Moher, D.; Schulz, K.F. Endorsement of the CONSORT Statement by high impact factor medical journals: A survey of journal editors and journal 'instructions to Authors'. Trials 2008, 9, doi:10.1186/1745-6215-9-20.

28. Plint, A.C.; Moher, D.; Morrison, A.; Schulz, K.; Altman, D.G.; Hill, C.; Gaboury, I. Does the CONSORT checklist improve the quality of reports of randomised controlled trials? A systematic review. Med. J. Aust. 2006, 185, 263-267.

29. Kane, R.L.; Wang, J.; Garrard, J. Reporting in randomized clinical trials improved after adoption of the CONSORT statement. J. Clin. Epidemiol. 2007, 60, 241-249.

30. Altman, D.G.; Simera, I.; Hoey, J.; Moher, D.; Schulz, K. EQUATOR: Reporting guidelines for health research. Lancet 2008, 371, 1149-1150.

31. Simera, I.; Moher, D.; Hoey, J.; Schulz, K.; Altman, D.G. A catalogue of reporting guidelines for health research. Eur. J. Clin. Invest. 2010, 40, 35-53.

32. Wager, E.; Field, E.A.; Grossman, L. Good publication practice for pharmaceutical companies. Curr. Med. Res. Opin. 2003, 19, 149-154.

33. Brazma, A.; Hingamp, P.; Quackenbush, J.; Sherlock, G.; Spellman, P.; Stoeckert, C.; Aach, J.; Ansorge, W.; Ball, C.A.; Causton, H.C.; Gaasterland, T.; Glenisson, P.; Holstege, F.C.; Kim, I.F.; Markowitz, V.; Matese, J.C.; Parkinson, H.; Robinson, A.; Sarkans, U.; Schulze-Kremer, S.; Stewart, J.; Taylor, R.; Vilo, J.; Vingron, M. Minimum information about a microarray experiment (MIAME)-toward standards for microarray data. Nat. Genet. 2001, 29, 365-371.

34. Goodacre, R.; Broadhurst, D.; Smilde, A.K.; Kristal, B.S.; Baker, D.J. Proposed minimum reporting standards for data analysis in metabolomics. Metabolomics 2007, 3, 231-241.

35. Stone, S.P.; Cooper, B.S.; Kibbler, C.C.; Cookson, B.D.; Roberts, J.A. The ORION statement: Guidelines for transparent reporting of outbreak reports and intervention studies of nosocomial infection. J. Antimicrob. Chemother. 2007, 59, 833-840.

36. Peters, J.L.; Sutton, A.J.; Jones, D.R.; Rushton, L.; Abrams, K.R. A systematic review of systematic reviews and meta-analyses of animal experiments with guidelines for reporting. J. Environ. Sci. Health B 2006, 41, 1245-1258.

37. O’Connor, A.M.; Sargeant, J.M.; Gardner, I.A.; Dickson, J.S.; Torrence, M.E.; Dewey, C.E.; Dohoo, I.R.; Evans, R.B.; Gray, J.T.; Greiner, M.; Keefe, G.; Lefebvre, S.L.; Morley, P.S.; Ramirez, A.; Sischo, W.; Smith, D.R.; Snedeker, K.; Sofos, J.; Ward, M.P.; Wills, R. The REFLECT statement: Methods and processes of creating reporting guidelines for randomised controlled trials for livestock and food safety. Prev. Vet. Med. 2010, 93, 11-18.

38. International Committee of Medical Journal Editors. Uniform Requirements for Manuscripts Submitted to Biomedical Journals. Available online: http:/www.icmje.org/urm_full.pdf (accessed on 22 January 2010). 
39. Council of Science Editors, Editorial Policy Committee (2008-2009). CSE's White Paper on promoting integrity in scientific journal publications (last updated on 2009). Available online: http://www.councilscienceeditors.org/editorial_policies/whitepaper/entire_whitepaper.pdf (accessed on 22 January 2010).

40. Committee on Publication Ethics (COPE). COPE best practice guidelines for journal editors. Available from: http://www.publicationethics.org/files/u2/Best_Practice.pdf (accessed on 22 January 2010).

41. Nuffield Council on Bioethics. The Ethics of Research involving Animals. Chapter 15: Discussion and Recommendations; pp 313, paragraph 15.58. 2005. Available online: http://www.nuffieldbioethics.org/fileLibrary/pdf/RIA_Report_FINAL-opt.pdf (accessed on 26 January 2010).

42. Drummond, G.B. Reporting ethical matters in The Journal of Physiology: Standards and advice. J. Physiol. 2009, 587, 713-719.

43. Osborne, N.J.; Payne, D.; Newman, M.L. Journal editorial policies, animal welfare and the 3Rs. Am. J. Bioeth. 2009, 9, 55-59.

44. Hooijmans, C.; Leenars, M.; Ritskes-Hoitinga, M. Improving the quality of publications on animal experiments to make systematic reviews possible. ALTEX 2009, 26, 262.

45. Wurbel, H. Publications should include an animal welfare section. Nature 2007, 446, 257.

46. Alfaro, V. Specification of laboratory animal use in scientific articles: Current low detail in the journal's instructions for authors and some proposals. Methods Find Exp. Clin. Pharmacol. 2005, 27, 495-502.

47. Nuffield Council on Bioethics. The Ethics of Research Involving Animals; Nuffield Council on Bioethics: London, UK, 2005. Available online: http://www.nuffieldbioethics.org/go/ browseablepublications/ethicsofresearchanimals/report_490.html (accessed on 22 January 2010).

48. Фbrink, K.J.; Rehbinder, C. Animal definition: A necessity for the validity of animal experiments? Lab Anim. 2000, 34, 121-130.

49. Boisvert, D.P. Editorial policies and animal welfare. In Animal Alternatives, Welfare and Ethics; Zutphen, L.F., Balls, M., Eds.; Elsevier: Amsterdam, The Netherlands, 1997; pp. 399-404.

50. Ellery, A.W. Guidelines for specification of animals and husbandry methods when reporting the results of animal experiments. Working Committee for the Biological characterisation of laboratory animals/GV-Solas. Lab Anim. 1985, 19, 106-108.

51. Moher, D.; Schulz, K.; Simera, I.; Altman, D.G. Guidance for developers of health research reporting guidelines. PLoS Med. 2010, 7, doi:10.1371/journal.pmed.1000217.

52. Mignini, L.E.; Khan, K.S. Methodological quality of systematic reviews of animal studies: A survey of reviews of basic research. BMC Med. Res. Methodol. 2006, 6, 10.

53. Macleod, M.R.; Collins, T.; Howells, D.W.; Donnan, G.A. Pooling of animal experimental data reveals influence of study design and publication bias. Stroke 2004, 35, 1203-1208.

54. Roberts, I.; Kwan, I.; Evans, P.; Haig, S. Does animal experimentation inform human healthcare? Observations from a systematic review of international animal experiments on fluid resuscitation. BMJ 2002, 324, 474-476.

55. Horn, J.; de Haan, R.J.; Vermeulen, M.; Limburg, M. Nimodipine in animal model experiments of focal cerebral ischemia: A systematic review. Stroke 2001, 32, 2433-2438. 
56. Kilkenny, C.; Browne, W.; Cuthill, I.C.; Emerson, M.; Altman, D.G. ARRIVE Guidelines. Animal Research: Reporting In Vivo Experiments: The ARRIVE Guidelines. J. Gene Med. 2010, 12, 561-563.

57. Kilkenny, C.; Brown, W.J.; Cuthill, I.C.; Emerson, M.; Altman, D.G. Animal Research: Reporting In Vivo Experiments: The ARRIVE Guidelines. Exp. Physiol. 2010, 95, 842-844.

58. Kilkenny, C.; Brown, W.J.; Cuthill, I.C.; Emerson, M.; Altman, D.G. Animal Research: Reporting In Vivo Experiments: The ARRIVE Guidelines. J. Physiol. 2010, 588, 2519-2521.

59. Kilkenny, C.; Brown, W.J.; Cuthill, I.C.; Emerson, M.; Altman, D.G. Animal Research: Reporting In Vivo Experiments: The ARRIVE Guidelines. Br. J. Pharmacol. 2010, 160, 1577-1579.

60. Kilkenny, C.; Brown W.J.; Cuthill, I.C.; Emerson, M. Altman, D.G. Animal Research: Reporting In Vivo Experiments: The ARRIVE Guidelines. Lab. Anim. 2010, doi:10.1258/la.2010.0010021.

(C) 2014 by the authors; licensee MDPI, Basel, Switzerland. This article is an open access article distributed under the terms and conditions of the Creative Commons Attribution license (http://creativecommons.org/licenses/by/3.0/). 